\title{
A Production Planning Model using Fuzzy Neural Network: A Case Study of an Automobile Industry
}

\author{
Rashmi Sharma \\ ABES Engineering College \\ Ghaziabad \\ India
}

\author{
Ashok K. Sinha \\ ABES Engineering College \\ Ghaziabad \\ India
}

\begin{abstract}
The production forecast based on order received is adversely affected by deterrent factors in supply chain management (SCM). Although several mathematical models have been attempted by researchers, the accuracy of such forecast still need to be improved. In the present paper the various deterrent factors influencing the supply chain have been considered adequately to forecast the production plan on the order received. The model is based on the machine learning using fuzzy neural network architecture and validated with real data on automobile production. The result is compared with that obtained by conventional multiple regression model and the former is found to be quite satisfactory, the error being as low as $2.9847 \mathrm{e}-006$
\end{abstract}

\section{General Terms}

Neural Networks, Fuzzy Systems, Decision Support System.

\section{Keywords}

Production Plan, Fuzzy Neural Network, Supply Chain Management, Machine Learning.

\section{INTRODUCTION}

The production forecasts based on order received are greatly influenced by operational obstacles in the different stages of supply chain management (SCM). These obstacles act as deterrent to the profitability of the industry. The supply chain includes movement and storage of raw material, work in process inventory, shipment process, finished goods from origin point to consumption point. Whole process of SCM is critically dependent on quantity of order received, lead time, procurement time, quality standards and inventory level of warehouses. It has been a challenge to identify and implement strategies that minimize uncertainties at each stage and thus improve the production targets.

In the last decades managers and researchers have done lot of studies and made efforts to monitor and measure the deterrence factors in SCM. Several mathematical models like time series, multiple regression, fuzzy systems and combination of them have extensively been implemented in the last few decades for modeling the critical deterrence factors directly affecting the production forecast. The most commonly used techniques include statistically based techniques like time series, regression techniques and computational intelligence method like fuzzy systems, artificial neural networks and neuro-fuzzy systems [1$3,4,5,8,10,11]$.

Yin-Yann Chen [6] proposed an allocation programming model considering multiple practical characteristics and constraints using linear programming. The product cost and transportation cost were the key factors to effect on the total cost. Heli Laurikkala, Mikko Ek, Juuso Rantala [7], suggested modeling and control of the supplier network in an e-logistics environment by using a system theoretical approach. Pisal Yenradeea, Anulark Pinnoib and Amnaj Charoenthavornying [9] applied three forecasting models: Winter's, decomposition, and Auto-Regressive Integrated Moving Average (ARIMA), to forecast the product demands, however the production deterrence factors are not adequately considered in the model. A Respicio, M.E. Captivo, A.J.Rodrigues[12] presented an agent-based Decision Support System(DSS) following a multi criteria optimization approach. An expert system incorporating three subsystems is described.

Gayialis Sotiris, Spanos Athanasios and Tatsiopoulos Ilias[13] presented a design of a production scheduling integrated with planning and control. Heilala et el [14], suggested a simulation based DSS used to help planners and schedulers organize production more efficiently.

In all these works, however, the deterrence factors in SCM have not been considered for modeling of the production plan. The findings suggested the potential value of neural networks for producing accurate forecasts and strengthening the decision making process. In the present paper the numbers of parameters which directly affect the production forecasts are considered. The approach used is machine learning, the principle of learning that can be adhered to machines to improve their performance. Neuro-Fuzzy (NF) computing is a popular framework for solving complex problems. For an organization to use NF approach the data and operations to be performed should be chosen fuzzy and the architecture and learning algorithm should be defined using neural model.

The proposed model in this paper can be used to estimate the Production plan of an automobile industry while considering the influence of some of the deterrent factors such as quantity ordered, lead time, procurement time, quantity in stock, products rejected due to quality constraints. This model is developed and tested from the data available for an automobile industry.

\section{METHODOLOGY}

\subsection{Hypothesis}

Traditional methods by several researchers were not giving appropriate results in forecasting of production plan in an automobile industry which lacks consideration for other variables largely affecting the forecast.

Assume that production plan forecast largely influenced by various factors $\mathrm{X} 1, \mathrm{X} 2, \mathrm{X} 3$, and $\mathrm{X} 4$ and $\mathrm{X} 5$. The parameters considered in this study are

$\mathrm{X} 1$ - lead time (time to deliver the required product), $\mathrm{X} 2$ - procurement time (time to receive raw material),

$\mathrm{X} 3$ - rejected products (reject at company level due to quality constraints),

X4 - quantity in stock (inventory level of warehouse),

X5 - quantity ordered (quantity ordered by customer). 
The output of the trained neuro-fuzzy network model is Production Plan (Y).

Production plan in an automobile industry is one of the real life problems falling in the category having uncertainty. The uncertainty lies in the automobile plant due to some uncontrolled parameters - quality of the raw material received, mode of shipment used to receive the raw materials and to deliver the received goods, the goods received back from the client which does not satisfies their quality standards variables are some of key contents. Past experience shows that the automobile production system may observe the large variation in production data as the system is effected by many uncertain production parameters and uncertain occurrence of long duration electricity failure, short of manpower for production during festivals or turn over, overtime schedules required for the urgent supply.

In this paper, a system is developed as shown in Figure 1 with inputs parameters as quantity ordered, lead time, rejected products, quantity in stock, procurement time for raw material and output is production plan of the product using neurofuzzy network model.

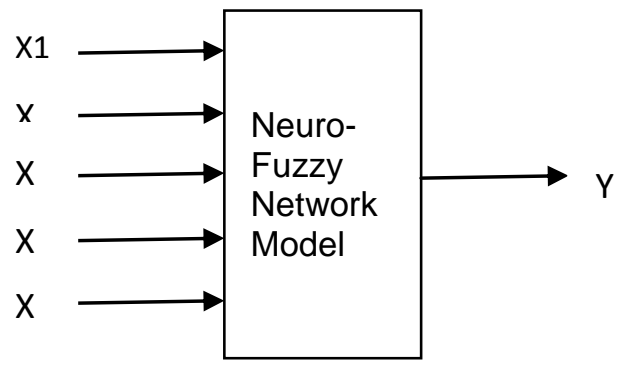

Figure 1 Input-output schematic of system

\subsection{Neural Network Architecture}

The neural network model used in the study is the multilayer perceptron (MLP) also known as a supervised network. This network requires a desired output in order to learn, achieved by creating a model that correctly maps the input to the output using historical data so that the model can then be used to produce the output when the desired output is unknown. This uses three-layer architecture: input (known parameters), hidden layer, and output layer (known value).

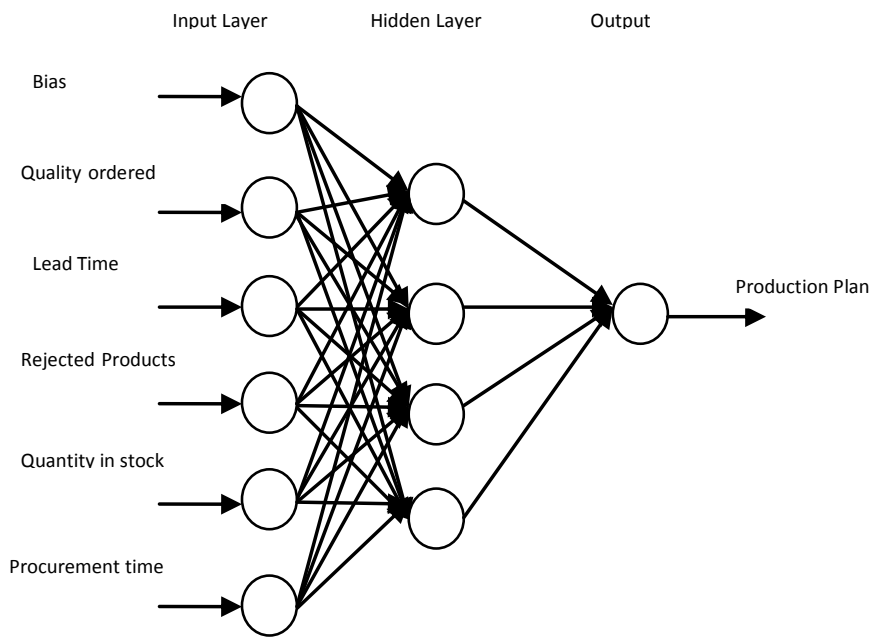

Figure 2 Neuro fuzzy models for Production Forecasting

\subsection{Proposed Method}

The procedure of the proposed method using neural network architecture model is given as follows:

1. Identify the input parameters which directly influence the supply of a product and in turn production of the product.

2. Collect the data for a period of time (data for the quantity ordered, lead time, procurement time, rejected products, quantity in stock). Normalize the collected data.

3. Design the model of Artificial Neural Network (ANN) with the consideration of number of layers, number of hidden layer and number of neurons in each of the layer.

4. Select the best suited algorithm to train the ANN.

5. Define the activation function for the each layer which suits the problem.

6. Decide the number of iterations and goal for the training of ANN.

7. Save the configuration of ANN

8. Now train the system with the collected data of previous years for selected parameters and actual productions as output.

9. Once the ANN is trained for the set goal then this system can be used to forecast the supply of products. Output of system will be taken as the forecast values for the corresponding year.

10. Error analysis is done with observed forecast values and actual production values to validate the designed model.

\subsection{Implementation}

\subsubsection{Data for Machine Learning}

A sample of data on quantity ordered, lead time, procurement time, rejected products, quantity in stock are shown in Table 1. The produced quantities are shown in Table 2. Both these data are used for machine learning.

Table 1. Historical data of sales order

\begin{tabular}{|c|c|c|c|c|c|c|}
\hline $\begin{array}{c}\text { S. } \\
\text { No }\end{array}$ & $\begin{array}{c}\text { Sales } \\
\text { order } \\
\text { date ( } \\
\text { mm/dd } \\
\text { / yyyy) }\end{array}$ & $\begin{array}{c}\text { Qua } \\
\text { ntity } \\
\text { Orde } \\
\text { red }\end{array}$ & $\begin{array}{c}\text { Lead } \\
\text { Time }\end{array}$ & $\begin{array}{c}\text { Reject } \\
\text { ed } \\
\text { produc } \\
\text { ts }\end{array}$ & $\begin{array}{c}\text { Quanti } \\
\text { ty in } \\
\text { stock }\end{array}$ & $\begin{array}{c}\text { Proc } \\
\text { urem } \\
\text { ent } \\
\text { time }\end{array}$ \\
\hline 1 & $\begin{array}{c}1 / 3 / \\
2007\end{array}$ & 500 & 10 & 12 & 38 & 8 \\
\hline 2 & $\begin{array}{c}2 / 8 / \\
2007\end{array}$ & 210 & 6 & 19 & 18 & 4 \\
\hline 3 & $\begin{array}{c}3 / 15 \\
/ 2007\end{array}$ & 250 & 3 & 36 & 22 & 4 \\
\hline 4 & $\begin{array}{c}4 / 5 / \\
2007\end{array}$ & 1000 & 8 & 77 & 69 & 6 \\
\hline 5 & $\begin{array}{c}5 / 3 / \\
2007\end{array}$ & 300 & 9 & 14 & 59 & 10 \\
\hline 6 & $\begin{array}{c}6 / 14 / \\
2007\end{array}$ & 2000 & 5 & 125 & 98 & 8 \\
\hline 7 & $\begin{array}{c}7 / 5 / \\
2007\end{array}$ & 500 & 4 & 48 & 100 & 6 \\
\hline 8 & $\begin{array}{c}8 / 3 \\
/ 2007\end{array}$ & 150 & 9 & 86 & 89 & 6 \\
\hline 9 & $\begin{array}{c}9 / 6 \\
/ 2007\end{array}$ & 500 & 9 & 52 & 90 & 8 \\
\hline 10 & $\begin{array}{c}10 / 4 \\
/ 2007\end{array}$ & 100 & 9 & 34 & 88 & 8 \\
\hline 11 & $\begin{array}{c}11 / 4 \\
/ 2007\end{array}$ & 400 & 7 & 67 & 81 & 8 \\
\hline $12 / 5 /$ & 100 & 6 & 55 & 70 & 6 \\
\hline 2007 & & & & & & \\
\hline
\end{tabular}


Table 2. Actual number of product produced (output of neural network model)

\begin{tabular}{|l|l|l|l|}
\hline S.No. & $\begin{array}{l}\text { Sales order date } \\
(\mathbf{m m} / \mathbf{d d} / \mathbf{y y y y})\end{array}$ & $\begin{array}{l}\text { Quantity } \\
\text { Ordered }\end{array}$ & $\begin{array}{l}\text { Quantity } \\
\text { produced }\end{array}$ \\
\hline 1 & $1 / 3 / 2007$ & 500 & 600 \\
\hline 2 & $2 / 8 / 2007$ & 210 & 220 \\
\hline 3 & $3 / 15 / 2007$ & 250 & 275 \\
\hline 4 & $4 / 5 / 2007$ & 1000 & 1150 \\
\hline 5 & $5 / 3 / 2007$ & 300 & 270 \\
\hline 6 & $6 / 14 / 2007$ & 2000 & 2150 \\
\hline 7 & $7 / 5 / 2007$ & 500 & 525 \\
\hline 8 & $8 / 3 / 2007$ & 150 & 175 \\
\hline 9 & $9 / 6 / 2007$ & 500 & 525 \\
\hline 10 & $10 / 4 / 2007$ & 100 & 110 \\
\hline 11 & $11 / 4 / 2007$ & 400 & 410 \\
\hline 12 & $12 / 5 / 2007$ & 100 & 115 \\
\hline
\end{tabular}

\subsubsection{Parameter of Neural Network and Results}

Parameters used in this study are

Input data - 76 patterns

Nodes in input layer - SIX (five parameters plus BIAS)

Hidden layer - ONE

Nodes in hidden layer - FOUR

Nodes in output layer - ONE

Weights assigned to each node in input layer (6)-hidden layer (4) $=\mathbf{2 4}$ weights

Weights assigned to each node in hidden layer (4) output layer $(1)=\mathbf{4}$ weights

Learning rate $(\eta)=\mathbf{0 . 3}$

Constant value $(\alpha)=\mathbf{0 . 5}$

Number of iterations $=\mathbf{9 0}$

Computer Program - .m file developed on MatLab

Mean Square Error $(\mathrm{MSE})=\mathbf{2 . 9 8 4 7 \mathrm { e } - 0 0 6}$

(as shown in Figure 3 and Figure 4)

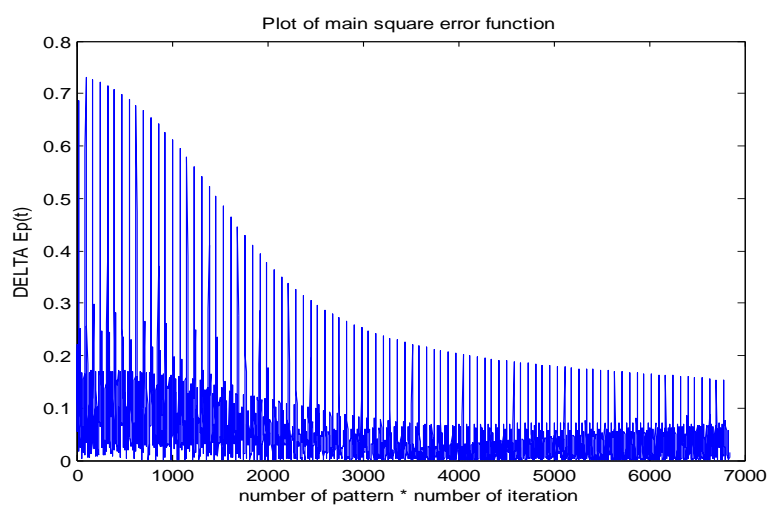

Figure 3 Graph plotting delta $E p(t)$ vs. count

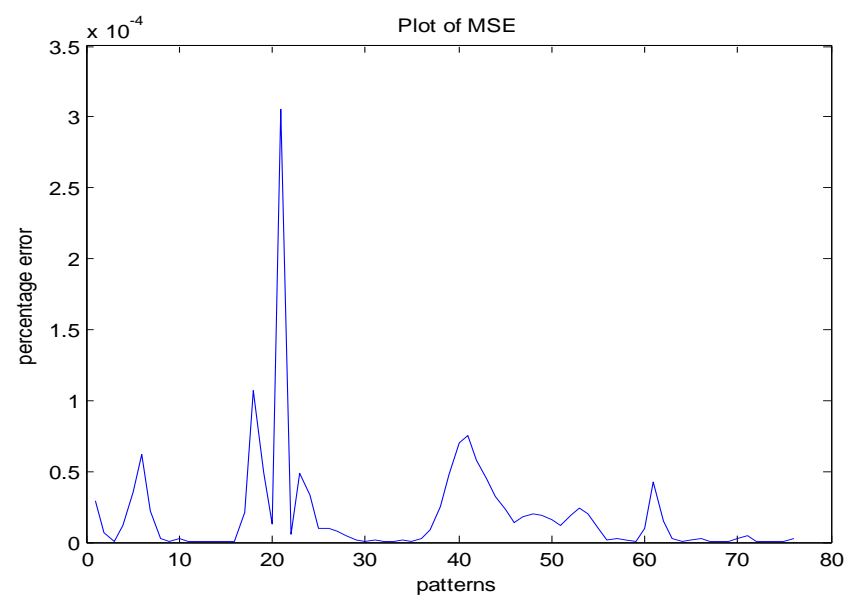

Figure 4 Graph plotting the patterns vs. \% error

\subsection{Comparison of above result with the results obtained by Multiple Linear Regressions}

For $100 \%$ confidence level the residuals lies between +0.07 to $-0.05$

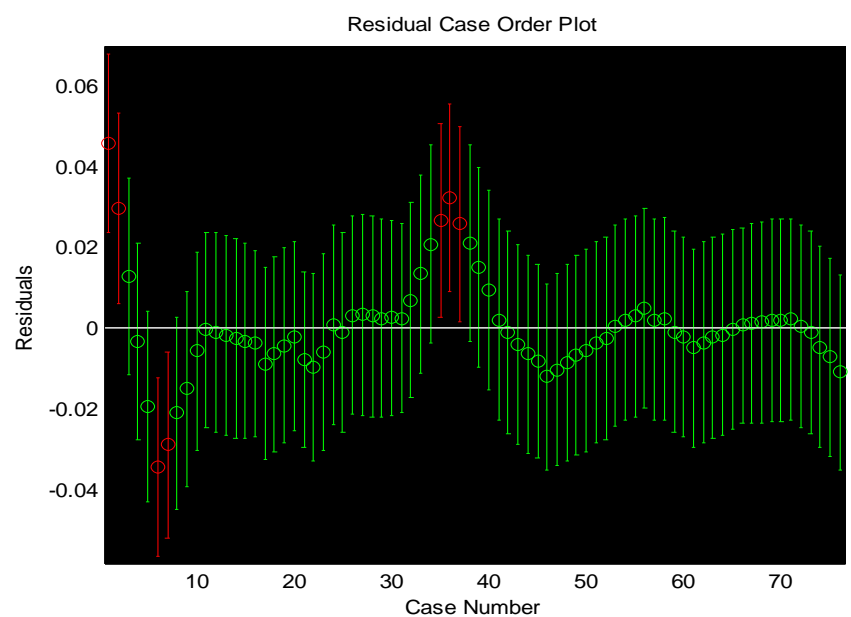

Figure 5 Residue case order plot (for $100 \%$ confidence level)

For $50 \%$ confidence level the residuals lies between +0.05 to -0.04 .

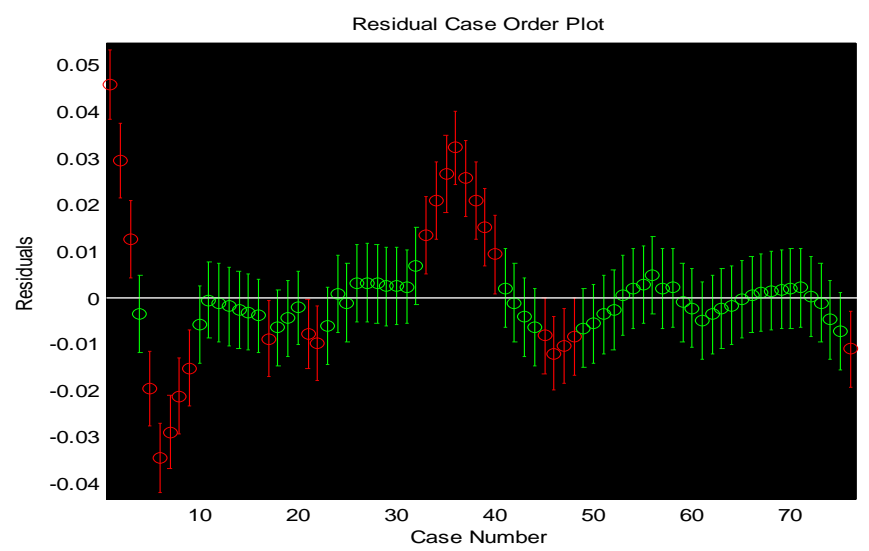

Figure 6 Residue case order plot (for $50 \%$ confidence level) 
In the first stage the model is trained with set input values of the pixel for known supply with random weights assigned. The error measures (actual value minus computed value) are distributed to the elements in the hidden layers using back propagation. Different weights connecting different elements in the network are corrected till the values converge within acceptable range.

\section{CONCLUSION}

In this study, the purpose was to model the influence of some of the critical deterrent factors on production plan of an automobile industry using neuro-fuzzy BP architecture. This helps in improving the forecast by reducing the forecast error to an acceptable value. These critical factors were also used to find the result for linear method. The linear method used was multiple linear regressions. The results obtained by multiple linear regressions method ranges between +0.05 to -0.04 . Whereas, the result obtained by neuro-fuzzy BP architecture is $2.9847 \mathrm{e}-006$.

Modeling of only some known parameters has been attempted for the sake of simplicity in this work for training data. It has been successfully implemented to model deterrent factors of the forecasting production plan of an automobile industry. The results suggest that ANN model with the developed structure can perform good prediction with least error and finally this neural network could be an important tool for supply forecasting.

\section{REFERENCES}

[1] J. Connors, D. Martin and L. Atlas, "Recurrent Neural network and robust time series prediction", IEEE Trans. Neural Network, Vol . 5, PP. $240-254$

[2] A. Weigend and N. Gerschenfeld, Eds., Time Series Prediction: Forecasting the future and Understanding the past reading, MA: Addision-Wesley, 1994

[3] A. Refenes and M. Azema-Baras, "Neural network application in financial asset management", Neural Comput. Applicat., Vol . 2, PP . 13-39, 1994

[4] Manski, Charles F. "Interpreting the Predictions of Prediction Markets," NBER Working Paper No. 10359, March 2004.
[5] Rajasekaran S,Vijayalakshmi G.A.,"Neural Networks, Fuzzy Logic and Genetic Algorithms", PHI, 2003

[6] Yin-Yann Chen "The Analysis of Different Production Planning Decision Models in the Supply Chain Network" Proceedings of the International Multi Conference of Engineers and Computer Scientists 2008 Vol II

[7] Heli Laurikkala, Mikko Ek, Juuso Rantala "Demand Forecast Based Modeling and Control of Supply Chain" IEEE transaction on neural network vol 15 pp. 108-113

[8] Luis F. Luna, Rafael Gutierrez, Roland Quintana "Lumpy Demand Forecasting Using Neural Networks “ IEEE transaction on neural network vol 15 pp 65-72

[9] Pisal Yenradeea, Anulark Pinnoib and Amnaj Charoenthavornying "Demand Forecasting and Production Planning for Highly Seasonal Demand Situations: Case Study of a Pressure Container Factory" research article Science Asia 27

[10] Demand Forecasting by neural fuzzy technique Escoda , A.Ortega, ASanz , A.Herms 0-780:3-37964/97/\$10.0001997IEEE ,FUZZ-IEEE'97 page no.13811386.

[11] Neural Network in supply chain , Horris C. bung , 95 Engineering Management-Conference , 0-7803-27993/95/\$4.00 O1995 IEEE, pg 347-352

[12] A DSS for Production Planning and Scheduling in the Paper Industry,A.Respicio,M.E.Captivo,A.J.Rodrigues, International Conference on Decision Making and Decision Support,DSIage July,2002

[13] A Decision Supprt System for Detailed Production Scheduling in a Greek Metal Forming Industry, Gayialis Sotiris ,Spanos Athanasios,Tatsiopoulos Ilias, MIBES transactions, Vol 2,Issue 1,Autumn 2008

[14] Developing Simulation-Based Decision Support System for Customer driven manufacturing operation Planning, Heilala, Montonen, Jarvinen, Kivikunnas, Mantila Silanpaa and Jokinen, Proceedings of the 2010 Winter Simulation Conference. 